\title{
What Is the Economic Impact of Infertility in Beef Cattle?'
}

\author{
Chris Prevatt, G. Cliff Lamb, Carl Dahlen, Vitor R. G. Mercadante, and Kalyn Waters²
}

Beef producers need cows to become pregnant, deliver healthy calves, and wean productive calves at a reasonable cost in order to make operations economically viable. Failure of breeding females to become pregnant adversely affects the economic viability of every beef operation. Some producers may not be aware of the significant negative impacts infertility has on their operations.

\section{Why do beef cows fail to become pregnant or wean a calf?}

Beef cows fail to become pregnant for numerous reasons, such as anestrus and prepuberty, diseases, poor body condition, calving difficulty, or a lower level of producer management. Cows and heifers may not start their estrous cycles during the breeding season. In addition, cows may become pregnant but fail to calve because they lose their pregnancy at some stage of gestation due to a disease or traumatic event. In any case, the adverse economic impacts of beef cows failing to calve and wean a calf are large.

Approximately $35 \%$ of all US beef producers use pregnancy detection as a management practice to determine if cows are pregnant and to make culling decisions. Pregnancy detection usually occurs about 30-90 days after the end of the breeding season. In the southeastern United States (including Florida), only $19 \%$ of producers use this tool to make culling decisions. Pregnancy diagnosis gives producers an opportunity to identify infertile cows and cull them before they spend additional money on an open cow that will not produce calf revenue.

However, removing these cows from the herd in an effort to maintain a steady population of brood cows may decrease a producer's ability to cull other cows that may fail to raise acceptable calves, or should otherwise be culled for legitimate production issues, such as age, temperament, structural concerns, and poor health. For the $65 \%$ (or in the southeastern United States, $81 \%$ ) of beef producers who do not use pregnancy diagnosis in their operations, the first opportunity they have to determine which cows are not pregnant is after the subsequent calving season. At that point, producers may decide to retain the cows that failed to calve, or cull those cows prior to the next breeding season. Either way, the producer has already incurred the costs of maintaining these cows for up to a year without producing a calf. With no calf sales from these unproductive cows, the costs of supplemented feed, pasture, veterinary medicine inputs and services, labor, machinery and equipment, and other expenses will decrease the current and lifetime profitability of the cowherd.

1. This document is AN208, one of a series of the Department of Animal Sciences, UF/IFAS Extension. Original publication date August 2008. Revised September 2018. Visit the EDIS website at http://edis.ifas.ufl.edu.

2. Chris Prevatt, state specialized agent, UF/IFAS Range Cattle Research and Education Center; G. Cliff Lamb, professor and department chair, Department of Animal Science, Texas A\&M University; Carl Dahlen, assistant professor, Department of Animal Sciences, North Dakota State University; Vitor R. G. Mercadante, assistant professor, Department of Animal and Poultry Sciences, Virginia Tech University; and Kalyn Waters, county Extension director, UF/ IFAS Extension Holmes County; UF/IFAS Extension, Gainesville, FL 32611.

The Institute of Food and Agricultural Sciences (IFAS) is an Equal Opportunity Institution authorized to provide research, educational information and other services

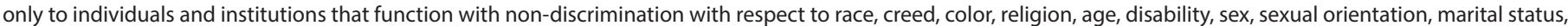

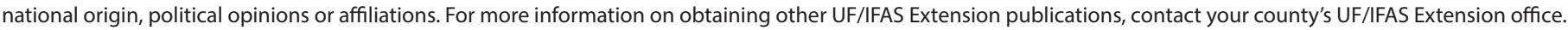
U.S. Department of Agriculture, UF/IFAS Extension Service, University of Florida, IFAS, Florida A \& M University Cooperative Extension Program, and Boards of County Commissioners Cooperating. Nick T. Place, dean for UF/IFAS Extension. 


\section{Which are the infertile beef cows?}

In order to identify the infertile beef cows in a beef cattle operation, cattle producers should consider implementing a defined breeding season of reasonable length (60-120 days). Approximately 30-90 days after the breeding season, a qualified person (beef producer, technician, veterinarian, etc.) should check the exposed beef cows and heifers for pregnancy using methods such as blood sampling, palpation, and ultrasound. The cows and heifers found open are deemed infertile for the given production cycle. These infertile cows can be managed differently or marketed to reduce production costs and improve profitability. In addition, some pregnancy checking methods can determine the number of months pregnant. Determining the number of months the cow or heifer is pregnant can help the producer identify late-bred cows, which are considered less fertile. Both of these types of infertility represent sizeable economic losses to the beef producer.

This document examines the economic loss associated with both infertile cows and less fertile, late-bred beef cows.

\section{What is the economic impact of infertile beef cows?}

Infertile cows that fail to wean a calf (cows and heifers that are identified as open, or those that become pregnant during breeding but do not wean a calf) simply do not give producers an opportunity to market a calf. Therefore, keeping an infertile cow with no prospects of economic return for the current production season requires the producer to incur the cost to carry this cow for up to one year as well as forgo the profits from the sale of the calf.

Table 1 displays the estimated annual economic loss of infertile beef cows for a 100-head cowherd using various percentages of infertile beef cows in the cowherd and annual economic loss per cow. The first column shows the annual production costs, which range from $\$ 500$ to $\$ 900$ per head per year. The second column is the average forgone net profits of a productive cow that weans a calf each year, which are assumed to be $\$ 200$ per cow. The sum of column one (annual production costs, \$/cow/year) and column two (forgone profits, \$/cow/year) represent the annual economic loss per cow per year, as shown in column three. The annual economic losses per cow per year range from $\$ 700$ to $\$ 1,100$. Multiplying the level of annual economic loss per cow times the number of infertile cows in the 100-head cowherd provides an estimate of the total annual economic loss for the 100-head cowherd.
The estimated total annual economic losses of infertile beef cows using a 100-head cowherd in Table 1 range from $\$ 2,800$ to $\$ 13,200$, depending on the number of infertile beef cows in the cowherd and annual economic loss per cow per year. If you assume an annual production cost of $\$ 700$ per cow per year and forgone profits of $\$ 200$ per cow per year resulting in an annual economic loss of $\$ 900$ per cow per year with an $8 \%$ level of infertile beef cows (8 head), the estimated total annual economic loss due to infertile beef cows is $\$ 7,200$ for the 100 -head cattle operation. Producers should attempt to reduce losses of this magnitude.

If the producer is able to reduce the percentage of infertile beef cows from $8 \%$ ( 8 head) to $6 \%$ (6 head), the annual economic loss would be reduced by $\$ 1,800(\$ 7,200-\$ 5,400)$ for a 100-head beef cow operation. If the producer is able to reduce both the percentage of infertile beef cows from $8 \%$ to $6 \%$ and the total economic loss from $\$ 900$ to $\$ 800$ per cow per year, the total annual economic loss is reduced by $\$ 2,400(\$ 7,200-\$ 4,800)$. Careful management and proper inputs can reduce the total annual economic loss due to infertile beef cows. It is important to understand that attempting to reduce the percentage of infertile beef cows to $0 \%$ is likely not the most economical course of action.

\section{What is the economic impact of less fertile beef cows?}

Beef producers need to consider the potentially large economic losses associated with less fertile beef cows and heifers. Less fertile beef cows become pregnant and calve later in the calving season. Table 2 shows the estimated reduced revenue of less fertile beef cows in a 100-head cowherd that has a 120-day breeding season. The cowherd is assumed to have a $90 \%$ weaning rate. In order to provide a basic economic example, a normal distribution of calving is assumed over the 120-calving season, which means half of the calves will be born during the first 60 days and the remaining half will be born during days 61-120. Lastly, all calves are assumed to be sold within one to two weeks at the end of the calf production period.

The second column in Table 2 describes the data for the beef cows calving during the first 60 days (days 1-60 of the calving season). The midpoint of the calving period is day 30 . We assumed that $90 \%$ of the 50 cows calving during the first 60 days would wean a calf, resulting in 45 calves. These calves were assumed to have an average weaning weight of 550 pounds per head. The average market price for these calves (medium-large frame, \#1 and \#2 muscle score) was 
estimated to be $\$ 1.42$ per pound (Prevatt 2009). The total calf weight for this group was 24,750 pounds $(550 \mathrm{lb} /$ calf $\mathrm{x} 45$ head). The average calf value was $\$ 781$ per head (550 $\mathrm{lb} /$ head $\times \$ 1.42 / \mathrm{lb}$ ). The total value of the 45 calves calving during the first 60 days was $\$ 35,145$ ( $\$ 781 /$ head $x 45$ head).

Column three describes the data for the beef cows calving during the second 60-day period (days 61-120 of the calving season). The midpoint of this calving period is day 90 . We assumed that $90 \%$ of the 50 cows calving during the second 60-day period would wean a calf, resulting in 45 calves. These calves were assumed to have an average weaning weight of 450 pounds per head. The average market price for these calves (medium-large frame, \#1 and \#2 muscle score) was estimated to be $\$ 1.50$ per pound (Prevatt 2009). The total calf weight for this group was 20,250 pounds ( $450 \mathrm{lb} /$ calf $\mathrm{x} 45$ head). The average calf value was $\$ 675$ per head ( $450 \mathrm{lb} /$ head $\mathrm{x} \$ 1.50 / \mathrm{lb})$. The total value of the 45 calves produced during the second 60 -day period was $\$ 30,375$ ( $\$ 675 /$ head $x 45$ head).

There is a significant difference between the total values of the two groups of calves, as seen in column four. Calves born during the second half of the calving season are lighter and bring fewer total dollars per head. The total reduced revenue of the less fertile beef cows was $\$ 4,770$ ( $\$ 35,145-$ $\$ 30,375)$. Producers who can move their cowherds to a 60 -day breeding season without incurring higher numbers of open cows can recover the $\$ 4,770$ annually. However, many producers will incur open cows in making the move to a shorter breeding season. While shortening the breeding season will take time to achieve, there can be significant economic incentive for producers to reduce the length of the breeding/calving season.

\section{Conclusion}

Producers cannot completely control infertility in their cowherds. However, understanding and addressing the factors that affect infertility will help producers implement management practices that can improve fertility and reduce the negative impacts of infertility on the profitability of beef cow-calf operations.

By making small changes within individual beef cattle operations, cattle producers can improve fertility and profitability. Collectively, Florida producers can make the Florida beef industry more profitable and sustainable by managing infertility in their cowherds. When extrapolated from the data reported by the National Animal Health Monitoring System (NAHMS 1997) and inventories accessed using the National Agricultural Statistics Service (NASS), the cost of infertility to the 908,000 beef cows owned by Florida beef producers exceeds $\$ 152$ million annually. In addition, the cost of infertility to all of the producers in the United States, which includes a beef cow population of over 31 million beef cows, exceeds $\$ 4.7$ billion annually. Individual beef producers can collect a significant portion of these economic losses with proper inputs, management, and a watchful eye.

\section{References}

NAHMS. 1997. "Part 1: Reference of 1997 Beef Cow-Calf Management Practices.” In NAHMS Beef '97. 1-55. Fort Collins, CO: USDA: APHIS: VS.

Prevatt, C. 2009. "Florida cattle market price watch." UF/ IFAS Range Cattle Research \& Education Center. Accessed on November 15, 2017. http://rcrec-ona.ifas.ufl.edu/ Florida\%20Cattle\%20Market\%20Price\%20Watch/price\%20 watch\%20index.shtml

USDA NASS. n.d. National Agricultural Statistics Service. Accessed on November 10, 2017. http://www.nass.usda.gov/ 
Table 1. Estimated total annual economic loss of infertile beef cows, 100-head cowherd.

\begin{tabular}{|c|c|c|c|c|c|c|c|}
\hline \multirow{4}{*}{$\begin{array}{l}\text { Annual Production } \\
\text { Costs (\$/cow/year) }\end{array}$} & \multirow{4}{*}{$\begin{array}{l}\text { Forgone Profits } \\
\text { (\$/cow/year) }\end{array}$} & \multirow{4}{*}{$\begin{array}{c}\text { Annual Economic } \\
\text { Loss } \\
\text { (\$/cow/year) }\end{array}$} & \multicolumn{5}{|c|}{ Percent of Infertile Beef Cows } \\
\hline & & & $4 \%$ & $6 \%$ & $8 \%$ & $10 \%$ & $12 \%$ \\
\hline & & & 4 head & 6 head & 8 head & 10 head & 12 head \\
\hline & & & \multicolumn{5}{|c|}{$\begin{array}{l}\text { Total Annual Economic Loss } \\
\text { (\$ per 100-head cowherd), \$/year }\end{array}$} \\
\hline$\$ 500$ & $\$ 200$ & $\$ 700$ & $\$ 2,800$ & $\$ 4,200$ & $\$ 5,600$ & $\$ 7,000$ & $\$ 8,400$ \\
\hline$\$ 600$ & $\$ 200$ & $\$ 800$ & $\$ 3,200$ & $\$ 4,800$ & $\$ 6,400$ & $\$ 8,000$ & $\$ 9,600$ \\
\hline$\$ 700$ & $\$ 200$ & $\$ 900$ & $\$ 3,600$ & $\$ 5,400$ & $\$ 7,200$ & $\$ 9,000$ & $\$ 10,800$ \\
\hline$\$ 800$ & $\$ 200$ & $\$ 1,000$ & $\$ 4,000$ & $\$ 6,000$ & $\$ 8,000$ & $\$ 10,000$ & $\$ 12,000$ \\
\hline$\$ 900$ & $\$ 200$ & $\$ 1,100$ & $\$ 4,400$ & $\$ 6,600$ & $\$ 8,800$ & $\$ 11,000$ & $\$ 13,200$ \\
\hline
\end{tabular}

Table 2. Estimated reduced revenue of less fertile beef cows (100-head cowherd, 120-day breeding season*).

\begin{tabular}{|c|c|c|c|}
\hline Data Measurements & $\begin{array}{l}\text { Calving During the } \\
\text { First } 60 \text { Days }\end{array}$ & $\begin{array}{l}\text { Calving During the } \\
\text { Second } 60 \text { Days }\end{array}$ & Value Differences \\
\hline One-half of breeding season, days & 60 & 60 & 0 \\
\hline Midpoint of days & 30 & 90 & -60 \\
\hline Beef cows, head & 50 & 50 & 0 \\
\hline Number of calves, head & 45 & 45 & 0 \\
\hline Average calf weight, lb/head & 550 & 450 & 100 \\
\hline Average calf price, $\$ / \mathrm{lb}$ & $\$ 1.42$ & $\$ 1.50$ & $-\$ 0.08$ \\
\hline Total calf weight, lb & 24,750 & 20,250 & 4,500 \\
\hline Calf value per head, $\$ /$ head & $\$ 781$ & $\$ 675$ & $\$ 106$ \\
\hline Total value of calves, $\$$ & $\$ 35,145$ & $\$ 30,375$ & $\$ 4,770$ \\
\hline Reduced revenue of less fertile beef cows, $\$ /$ year & & & $\$ 4,770$ \\
\hline
\end{tabular}

